\title{
REPRESENTASI IMPERIALISME BUDAYA KOREA DALAM IKLAN NUTRISARI VERSI “JUNG MIN BUTUH VITAMIN"
}

\author{
Ratu Laura M.B.P' ${ }^{1}$, Ratu Nadya Wahyuningratna ${ }^{2}$ \\ 1,2 Program Studi IImu Komunikasi, Universitas Pembangunan Nasional Veteran Jakarta
}

Naskah diterima tanggal 06-11-2020, direvisi tanggal 15-01-2021, disetujui tanggal 16-01-2021

\begin{abstract}
Abstrak. Istilah K-Pop dan K-Wave saat ini tidak asing lagi didengar. Kedua istilah tersebut sangat erat dengan kebudayaan Korea Selatan yang sedang menyebar tidak hanya di Indonesia namun juga di seluruh dunia. Saat ini semua orang dapat dengan mudah mengakses segala hal yang berhubungan dengan kebudayaan Korea Selatan melalui media cetak, elektronik maupun online. Koreanisasi menjadi bentuk baru dari imperialism budaya. Di Indonesia, demam Korea hadir dalam berbagai industri musik, drama, kecantikan, kuliner maupun fashion. Beberapa produsen dari brand-brand besar pun mulai membuat dan mengikuti tren pembuatan iklan ala Korea. Salah satu iklan bernuansa Korea adalah iklan Nutrisari Versi "Jung Min Butuh Vitamin". Dengan menggunakan analisis semiotika Roland Barthes, penelitian ini ingin mengetahui bagaimana representasi imperialism budaya Korea dalam sebuah iklan. Berdasarkan hasil penelitian diketahui bahwa iklan Nutrisari versi "Jung Min" mengandung nilainilai imperialisme budaya yang kuat.
\end{abstract}

Kata kunci: Budaya, Imperialisme, Korea Selatan, Representasi, Semiotika

Abstract: K-Pop and K-Wave terms are now familiar to hearing. Those are very closely related to South Korean culture which is spreading not only in Indonesia but also throughout the world. Nowadays, everyone can easily access everything related to South Korean culture through print, electronic and online media. Koreanization becomes a new form of cultural imperialism. In Indonesia, Korean fever is present in various music, drama, beauty, culinary and fashion industries. Several producers from big brands have started to create and follow the trend of making Korean-style advertisements. One of the advertisements with a Korean nuance is Nutrisari ad version of "Jung Min Needs Vitamins". By using Roland Barthes' semiotic analysis, this research wants to know how the representation of Korean cultural imperialism in an advertisement. Based on the research results, it is known that the Nutrisari advertisement version of "Jung Min" contains strong cultural imperialism values.

Keywords: Culture, Imperialism, South Korea, Representation, Semiotic

\section{PENDAHULUAN}

Dominasi budaya dalam dua dekade terakhir tidak lagi berasal dari budaya barat. Salah satu negara Asia, Korea Selatan, mulai menempatkan budayanya sebagai budaya yang banyak diikuti dan diminati di dunia dengan penyebaran yang begitu masif. Berbagai budaya Korea seperti musik, film, drama, makanan mendominasi media-media di seluruh dunia. Melalui berbagai saluran dan banyaknya prestasi, gelombang Korea atau yang lebih dikenal sebagai Korean Wave mengokohkan diri menjadi salah satu pusat budaya dunia.

Perkembangan budaya dari negeri gingseng yang sangat pesat ini juga menjamur di Indonesia. Korea menjadi salah satu budaya popular dengan penyebaran media massa yang begitu tinggi. Budaya popular adalah budaya yang hadir dan dapat menghilang secara tiba-tiba. Budaya menjadi sebuah budaya popular karena adanya kontribusi media massa (Gogali, 2016, hal.33). 
Salah satu yang paling terkena dampak $K$-wave adalah para penggemar fanatik K-Pop yang sebagian besar berasal dari kalangan remaja. Mereka tak segan-segan menghabiskan uang untuk membeli album, merchandise dan segala hal yang berkaitan dengan idolanya sebagai bentuk apresiasi dan kecintaannya terhadap idola tersebut. Dalam era post-modern saat ini, hal tersebut menggambarkan betapa dunia hiburan Korea mengomodifikasi berbagai hal agar menjadi sumber uang.

Pesatnya penyebaran budaya Korea di Indonesia telah membuat masyarakat dari berbagai usia terjangkit demam budaya Korea yang kerap disebut "Hallyu". Disadari atau tidak, sudah banyak masyarakat yang mengimitasi budaya Hallyu dalam bentuk pakaian, cara berbicara, makanan, dan lifestyle. Demam ini tak lagi membuat Korea menjadi salah satu budaya popular, tetapi sebagai bentuk imperialisme budaya.

Penelitian Ardian (2017) membahas komunikasi dalam perspektif imperialisme kebudayaan. Menurut Ardian (2017), imperialisme budaya di era reformasi, tampak semakin menonjol dibandingkan era rezim sebelumnya yang memengarhui segala sendi-sendri kehiduapan ekonomi, politik, dan budaya. Lebih lanjut diketahui imperialisme kebudayaan kini, bukan hanya dari Barat, melainkan juga dari nonBarat seperti India, Korea, Cina, Jepang, dan Turki. Pemanfaatan media sosial diketahui sangat memengaruhi produk kebudayaan pop yang datang dari tiap penjuru dunia. Kegandrungan remaja akan KPOP membuat boyband dan girlband asal Korea menjadi trendsetter dan mengakitkan imperialisme budaya non Barat semakin deras memasuki Indonesia.

Perkembangan imperialisme budaya Amerika diteliti pula oleh Febiola (2017) yang membahas mengenai representasi imperialisme budaya Amerika dalam musik video. Penelitian ini ingin mengetahui bagaimana Amerika menyebarkan hegemoni budayanya melalui media massa menggunakan analisis semiotika John Fiske. Berdasarkan hasil penelitian diketahui bahwa imperialisme budaya Amerika begitu kuat dalam musik video tersebut sehingga budaya lain pun terkikis keberadaannya.

Sementara itu, penelitian lain milik Valentina dan Istriyani (2013) membahas mengenai merebaknya Korean Wave sebagai akibat dari arus globalisasi yang melanda Indonesia. Media diketahui turut memiliki andil dapat menyebarkan budaya Korea kepada masyarakat. Pengemasan produk budaya Korea Selatan secara simultan dan kompleks memengaruhi selera masyarakat secara keseluruhan, mulai dari lagu, bahasa, fashion, makanan, sampai dengan tempat-tempat tersebut.

Teori imperialisme budaya pertama kali dikemukakan oleh Herb Schiller pada tahun 1973. Menurut Schiller (dalam Nurudin, 2007), negara Barat mendominasi media di seluruh dunia ini. Dengan kata lain, negara barat mendominasi media massa di dunia ketiga. Masyarakat dari dunia ketiga akan mengimitasi budaya barat melalui media. Ketika proses peniruan ini terjadi, maka terjadilah penghancuran budaya asli di negara ketiga. Schiller (1979) mendefinisikan imperialism budaya sebagai berikut: "Sum of the processes by which a society is brought into the modern world system and how its dominating stratum is attracted,pressured, forced, and sometimes bribed into shaping social institution to correspond to, or even promote, the value and structures of the dominating center of the system". (Schiller, 1979).

Menurut Shim (2006) Koreanisasi adalah bentuk baru dari imperialisme budaya. Secara perlahan tapi pasti masyarakat di dunia tak lagi menjadikan budaya barat sebagai pusat dari segala budaya. K-Wave merupakan efek yang diinginkan dari strategi negara yang dirancang khusus untuk mengekspor produk-produk hiburan Korea ke luar negeri. Anggaran sektor budaya telah berkembang pesat sejak masa pemerintahan Presiden ke-8, Kim Dae Jung yang menyebut dirinya sebagai "Presiden Budaya".

Imperialisme budaya Korea Selatan ini berlangsung di Indonesia dalam berbagai industri musik, drama, kecantikan, kuliner maupun fashion. Beberapa produsen dari brandbrand besar pun mulai membuat dan mengikuti tren pembuatan iklan ala Korea. Beberapa di antaranya Sabun Mandi Korea Glow dan Molto aroma K-Romance (Unilever), Mie Sedaap Korean Spicy Chicken dan Lucas Neo Coffee (Wings Group) serta masih banyak lagi. 
Dari sekian banyak iklan berkonsep Korea, terdapat satu iklan bertema K-Wave yang menarik sebab mengangkat budaya Korea secara keseluruhan. Iklan tersebut adalah iklan Nutrisari versi “Jung Min Butuh Vitamin!" yang memperlihatkan beberapa budaya Korea modern dan tradisional. Iklan ini tayang pada bulan Februari 2019 dengan seorang talent yang bernama Jung Min. Dalam iklan tersebut ia menyatakan kesibukannya sebagai aktor dengan banyak kegiatan namun tetap membutuhkan vitamin yang akhirnya ia dapatkan dari produk Nutrisari varian Jeju Orange. Iklan minuman ini memperlihatkan bagaimana kehidupan seorang artis Korea yang berakting dengan segala macam peran bertemakan Korea.



Gambar 1. Iklan Nutrisari Jeju Orange

Sumber: (akun Youtube Nutrisari ID, 2019)

Penggambaran yang diperlihatkan oleh karakter Jung Min ini seolah merepresentasikan bagaimana kehidupan artis dan idola Korea pada umumnya. la menggunakan pakaian warna mencolok diiringi penari latar perempuan berpakaian agak sensual, menggeluti banyak peran sebagai seorang aktor, dan dikelilingi oleh banyak penggemar yang memujanya. Berbagai representasi tersebut dikemas dalam budaya Korea modern dan tradisional. Representasi sendiri merupa $\neg$ kan konsep yang digunakan dalam proses sosial yaitu pemaknaan melalui sistem penandaan yang terse-dia, seperti dialog, tulisan, video, film, fotografi. Representasi menunjuk baik pada proses maupun produk dari pemaknaan suatu tanda. Representasi merujuk kepada konstruksi sega $\urcorner$ la bentuk media (terutama media massa) terha $\mathrm{ddap}$ segala aspek realitas atau kenyataan, seperti masyarakat, objek, peristiwa, hingga identitas budaya (Kodri, 2016, hal.53).

Berdasarkan pemaparan tersebut, peneliti tertarik untuk menganalisis representasi yang disajikan dalam Iklan Nutrisari versi "Jung Min Butuh Vitamin!" dengan kaitannya dengan imperialisme budaya Korea dengan menggunakan Semiotika Roland Barthes. Semiotika dalam penelitian ini sendiri menggunakan pendekatan melalui gagasan signifikasi dua tahap Roland Barthes (two order of signification). Ahli semiotika Perancis, Roland Barthes (1915-1980) menggambarkan menggunakan kekuatan penggunaan semiotika untuk membongkar struktur makna yang tersembunyi dalam tontonan, pertunjukan sehari-hari, dan konsep-konsep umum.(Danesi, 2010, hal.12).

\section{A. Rumusan Masalah}

Berdasarkan latar belakang masalah di atas, maka perumusan masalah dalam penelitian ini adalah "Bagaimana makna Imperialisme Budaya Korea yang direpresentasikan dalam Iklan Nutrisari versi "Jung Min Butuh Vitamin!" dengan menggunakan Semiotika Roland Barthes? 


\section{METODE PENELITIAN}

Metode pengumpulan data dalam penelitian ini adalah mengamati Iklan Nutrisari versi "Jung Min Butuh Vitamin!" di televisi guna memperoleh data yang dibutuhkan. Iklan diamati dengan cara observasi tidak langsung karena objek yang diamati ada ditayangkan di televisi yaitu dengan mengamati slide atau cuplikan iklan-iklan tersebut di internet karena penayangan di televisi tidak dapat diketahui dengan pasti waktunya. Peneliti juga melakukan studi literatur yaitu mengumpulkan data dengan cara memperbanyak membaca buku, jurnal, internet, dan karya-karya ilmiah. Penelitian ini dilakukan dengan pendekatan kualitatif dengan metode analisis Semiotika Roland Barthes untuk mengetahui secara detail representasi imperialism budaya Korea Selatan dalam iklan tersebut. Roland Barthes mengungkapkan bahwa saat ini mitos adalah sebuah pesan-bukan konsep, gagasan, ataupun objek (Gora, 2016, hal.165).

Teori yang digunakan adalah imperialisme budaya adalah oleh Herb Schiller (1973). la mengatakan bahwa negara - negara barat mendominasi media di negara dunia ketiga sehingga menimbulkan efek yang begitu besar dan mempengaruhi budaya di negara dunia ketiga. la mendefinisikan imperialisme budaya itu sendiri adalah jumlah proses dimana masyarakat dibawa ke dalam sistem dunia modern dan bagaimana strata dominasinya ditarik, ditekan, dipaksa, dan kadang-kadang disuap untuk membentuk institusi sosial untuk menyesuaikan dengan, atau bahkan mempromosikan, nilai dan struktur dari pusat yang mendominasi dari sistem.

Efek utama yang ditimbulkan oleh imperialisme budaya adalah hilangnya budaya asli di negara dunia ketiga (Schiller, 1973, dikutip dari Febiola, 2017, hal.4). Secara ringkas Baran mengungkapkan imperialisme budaya merupakan invasi dari negara - negara asing yang powerful terhadap suatu kultur masyarakat asli atau pribumi melalui media massa (Baran, 2004, dikutip dari Febiola, 2017, hal.4 ).

\section{HASIL DAN PEMBAHASAN}

\section{A. Identifikasi Umum Iklan}

Iklan Nutrisari versi “Jung Min Butuh Vitamin!" pernah tayang di televisi nasional pada awal tahun 2019 dan diunggah pada bulan Februari 2019 di akun Youtube NutrisarilD. Tema dari iklan ini sendiri adalah seorang superstar bernama Jung Min yang memiliki segudang aktivitas keartisan seperti menjadi seorang aktor, penyanyi dan berolahraga serta jumpa fans.

Tokoh Jung Min sendiri merupakan orang asli Korea Selatan, informasi ini peneliti dapatkan sendiri dari admin akun Instagram Nutrisari. Laki-laki bertubuh tinggi dengan raut wajah khas asia timur itu cuukup fasih berbahasa Indonesia sehingga bisa menyampaikan pesan iklannya dengan sangat baik. Nutrisari sendiri meluncurkan varian baru rasa jeju orange ini karena mengandung banyak vitamin dan mineral yang baik bagi tubuh yaitu vitamin $A, B 1$, B3, B6, Asam Folat, Vitamin C, E, kaslium dan Fosfor (Nurtimart, n.d., para. 2). Buah Jeruk yang tumbuh di Kepulauan Jeju, Korea Selatan ini memang terkenal dengan banyak manfaat, dengan kadar manis 16 kali lipat dar jeruk biasanya dan Kelebihan lain buah ini memiliki ukuran yang lebih besar dan kadar air yang lebih banyak dari jeruk pada umumnya (Vitaarum, 2016, para.2).

\section{B. Pembahasan}

Dalam menganalisis representasi imperialisme budaya Korea Selatan ini, peneliti mengambil beberapa potongan scene dari iklan Nutrisari veri "Jung min Butuh Vitamin!" 


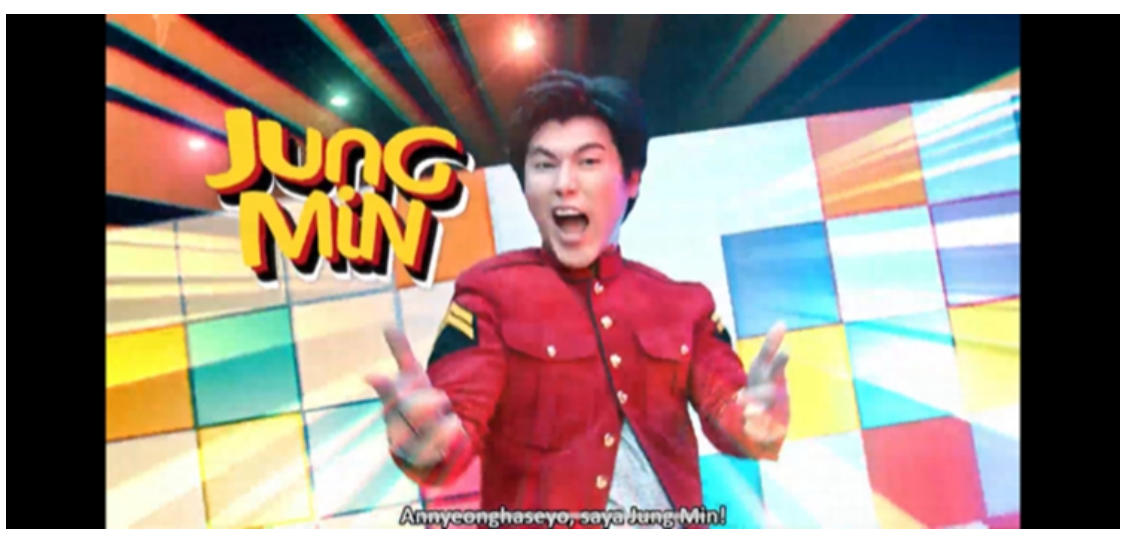

Gambar 2. Scene 1

Sumber: (akun Youtube Nutrisari ID, 2019)

(Shoot: Medium Shot)

Makna denotasi: seorang pria berjaket ala militer dengan latar ruangan pernuh lampu warna warni dan lagu upbeat, memberikan salam dalam dua Bahasa yaitu "anyeonghaseyo" yang merupakan Bahasa Korea dan dilanjut dengan "saya Jung Min!" yaitu Bahasa Indonesia. Lelaki tersebut memiliki paras khas asia timur dengan kulit putih dan mata sipit.

Makna konotasi: seorang tokoh berdarah Korea Selatan yang memperkenalkan dirinya dengan nama Jung Min dalam dua Bahasa (Korea dan Indonesia) ia memperlihatkan style-nya sebagai seorang selebriti dengan jaket militer berwarna berani dan latar ruangan warna warni seperti yang biasa digunakan oleh para idola khas negeri ginseng tersebut saat perfom atau membuat music video.

Mitos: Sapaan dalam bahasa Korea sudah lazim digunakan dan dipahami oleh masyarakat di berbagai belahan dunia. Melalui media massa, masyarakat belajar menggunakan bahasa Korea yang didapat dari lagu juga drama. Korea Selatan dikenal juga sebagai negara yang memiliki militer yang kuat, dan semua laki-laki diwajibkan untuk mengikuti wajib militer.

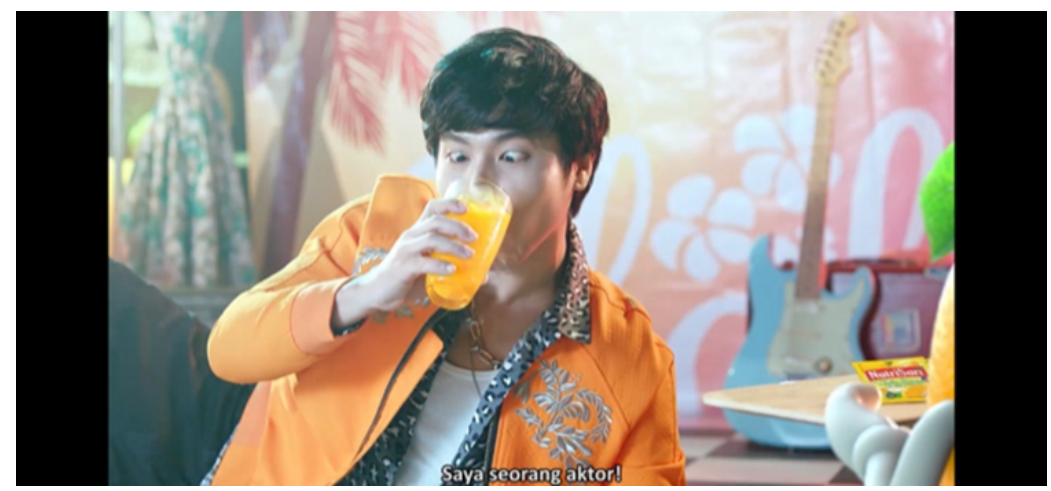

Gambar 3. Scene 2

Sumber: (akun Youtube Nutrisari ID, 2019)

(Shoot: Medium Shoot)

Makna denotasi: seorang pria dengan busana berwarna "flashy" mencolok mengungkapkan dirinya yang seorang aktor sambil meneguk minuman jeruk yang sangat matching dengan style-nya. Terlihat juga si maskot Nutrisari di sebelahnya membawa kemasan Nutrisari varian Jeju Orange.

Makna konotasi: laki-laki bernama JungMin yang mengaku sebagai aktor dengan style mencolok dan tidak biasa, ia sedang meneguk Nutrisari varian Jeju Orange yang dibawakan oleh si Maskot Nutrisari. 
Mitos: Korea Selatan dikenal sebagai salah satu negara "kiblat fashion" yang diakui dunia. Dilansir dari cosmogirl.co.id, Industri kreatif Korea Selatan sangat cepat 'menangkap' pergerakan tren. Grup k-pop tahun 2000 diketahui sangat 'eksperimental'. Banyak yang bilang orang Korea terlalu self-conscious, tapi satu hal positif yang bisa kita ambil adalah: they know how to look cool (Rachel, 2017, para.4).

Pria dan wanita di negeri ginseng tersebut dikenal sangat stylish dan menjadi contoh trendsetter bagi masyarakat di seluruh dunia. Sudah terbukti banyak sekali aktor dan para idola dari negeri ginseng tersebut memiliki jutaan fans dari belahan dunia. Pakaian ala pria Korea Selatan memang beda dari negara-negara lainnya (Radar Jogja, 2019, para.1). Mereka terlihat tidak segan-segan menggunakan warna mencolok, potongan baju yang tidak biasa dan aksesoris yang beragam. Dan style seperti ini mulai banyak dicontoh oleh pria di berbagai belahan dunia sebagai acuan trend fashion terkini.

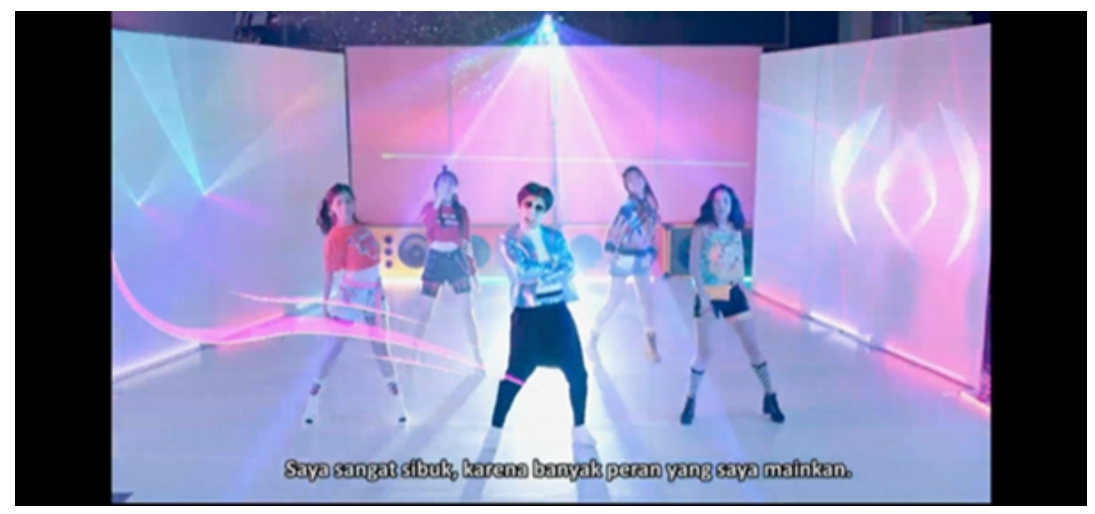

Gambar 4. Scene 3

Sumber: (akun Youtube Nutrisari ID, 2019)

(Shoot: Long Shoot)

Makna Denotasi: seorang pria menggunakan pakaian mengkilap dan celana berpotongan tidak biasa sedang berdansa di sebuah set yang sering digunakan untuk syuting music video dengan empat penari latar di belakangnya yang mengenakan baju berwarna warni.

Makna konotasi: seorang pria sedang berdansa ala Kpop dengan bajunya yang mencolok dan penari latar khas idola dari Korea Selatan. Set latar yang digunakan pun sangat khas seperti yang biasa digunakan oleh artis-artis idola dalam music videonya, yaitu berwarnawarrni dan dipenuhi sorot lampu.

Mitos: menjadi idola Kpop selama satu decade ke belakang merupakan suatu profesi yang banyak diimpikan oleh banyak remaja di Korea Selatan. Mereka rela menghabiskan bertahun-tahun untuk berlatih di agensi hiburan tertentu demi bisa debut menjadi idola seperti yang mereka impikan. Ketenaran dan pesona selebritis yang dimiliki oleh para idola inilah yang membuat mereka berlomba-lomba untuk bisa debut menjadi idola di negaranya tersebut.

Tak hanya di negaranya sendiri, bisnis Kpop juga menjadi pasar yang sangat menguntungkan di seluruh dunia termasuk di Indonesia dengan notabe para penggemarnya yang sangat banyak. Dilansir dari Kompasiana.com, Di Indonesia sendiri terdapat banyak sekali orang yang menyukai Kpop dan juga budaya Korea itu sendiri. Idol K-pop yang sangat banyak di kenal oleh masyarakat misalnya seperti, BTS, Seventeen, EXO, Wanna One, Super Junior, Monta X, Twice, GFriend, Apink, KARD, dan masih banyak lagi. Pada tahun ini saja sangat banyak idola K-pop yang berbondong-bondong untuk melakukan konser di Indonesia (Andreeany, 2018).

Pendapatan yang mengalir dari Indonesia sangat patut diperhitungkan. Ini dipahami betul oleh bintang K-Pop sampai-sampai mereka sangat menjaga interaksi dengan penggemar Indonesia. Apalagi, sebagai negara berpenduduk besar, Indonesia berpotensi membuat karyakarya mereka melejit hanya dari YouTube (Putri, 2020). 


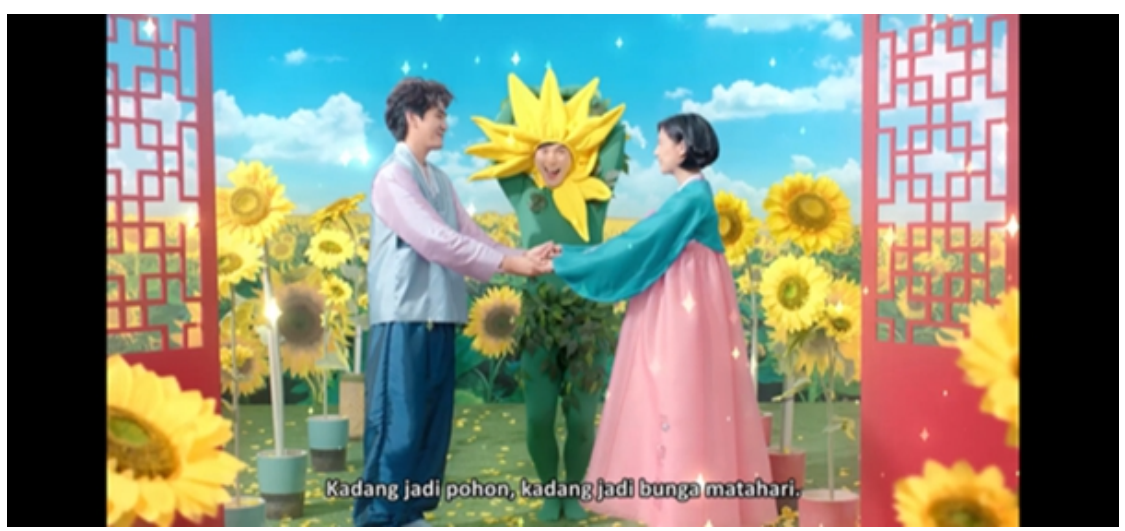

Gambar 5. Scene 4

Sumber: (akun Youtube Nutrisari ID, 2019)

(Shoot: Long Shoot)

Makna denotasi: sepasang laki-laki dan perempuan sedang berpegangan tangan dan saling bertatapan, mereka menggunakan baju tradisional khas Korea Selatan. Di latarnya terlihat pintu berukir yang juga menjadi khas Korea Selatan dan seorang laki-laki berkostum Bungan matahari sebagai latarnya.

Makna konotasi: sebuah adegan romantis yang dilakoni oleh sepassang laki-laki dan perempuan seperti drama klasik khas Korea Selatan dengan busana hanbok yang mereka kenakan dan pintu berukir klasik khas rumah negeri ginseng tersebut (hanok). Terlihat juga Jung Min yang berperan sebagai bunga matahari yang membuat suasana menjadi lebih ceria.

Mitos: sejarah perkembangan budaya Korea Selatan yang mulai digemari masyarakat Indonesia tidak lepas dari peran drama-drama negeri tersebut yang sangat diminati oleh remaja hingga kaum dewasa. Jauh sebelum fashion dan musik, Drama Korea telah berhasil mengambil hati banyak orang di dunia. Drama Korea telah berhasil lebih dahulu mendunia baik di Asia maupun di Amerika. Drama televisi Korea banyak didasarkan pada cerita romantis, fakta sejarah yang menggambarkan kisah-kisah nyata dari masa lalu, thriller, drama keluarga, dan komedi, serta drama yang menggabungkan dari satu atau lebih kategori (Ardia, 2014, hal. 11).

Tema yang beragam dari yang berlatar modern hingga kolosal sangat dikemas dengan menarik dan bisa diterima oleh berbagai kalangan. Sebut saja drama Scarlett Heart Ryeo yang dibintangi oleh artis-artis papan atas seperti Lee Jieun (IU), Baekhyun EXO hingga Nam Joohyuk yang bercerita tentang gadis muda yang hidup di abad 21, tiba-tiba ia "Kembali" ke Dinasti Gryeo di masa lampau. Penampakan hanok (rumah tradisional) dan hanbok (baju tradisional) khas negara tersebut diperlihatkan dengan apik dan memberikan nilai sejarah bagi para penontonnya. "Scarlet Heart Ryeo" milik stasiun TV SBS mengawali debut dengan rating 7,4 persen di episode pertama. Kemudian menjadi 9,3 persen pada episode ke-2 yang ditayangkan berturut-turut di hari yang sama (Zetizen, 2016.

Scene ini dengan jelas memperlihatkan bagaimana budaya Korea Selatan dengan halhal yang berbau tradisional hingga adegan bak dramanya begitu tidak asing bagi masyarakat Indonesia. Diperlihatkan juga pemandangan indah dengan pemandangan bunga matahari khas daerah Gangju. Jalan-jalan ke Korea saat musim panas, pastikan kamu mampir ke kebun bunga matahari di Gangju Cultural Village, Haman, Provinsi Gyeongsang Selatan. para petani di Haman menanam satu juta pohon bunga matahari di lahan seluas 48 ribu meter persegi (Dewi, D.K., 2019, para.2) 


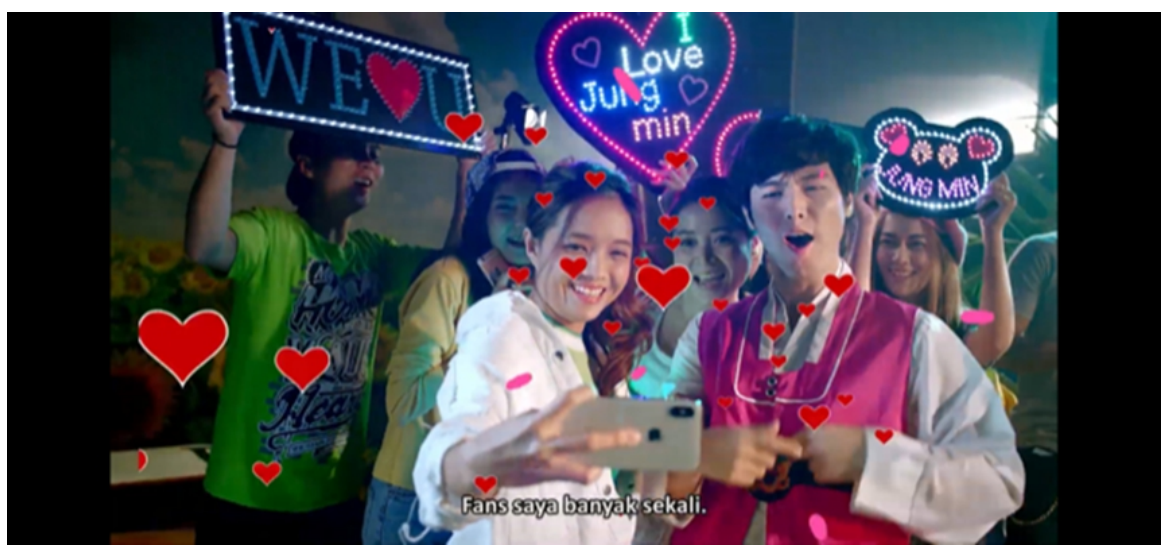

Gambar 6. Scene 5

Sumber: (akun Youtube Nutrisari ID, 2019)

(Shoot: Medium Shoot)

Makna denotasi: seorang pria mengenakan baju tradisional Korea (hanbok) dan diajak berfoto oleh seorang perempuan dengan ponselnya. Terlihat di belakangnya kerumunan orang mengangkat light sign dengan berbagai tulisan.

Makna konotasi: seorang pria (Jung Min) yang diajak berfoto oleh para fansnya, ia mengatakan bahwa fans (penggemarnya) banyak sekali sehingga bisa diartikan bahwa kumpulan orang di belakangnya yang membawa light sign sudah pasti adalah fansnya. Dari light sign tersebut juga terlihat nama Jung Min terukir. Sudah menjadi rahasia umum bahwa para penggemar dari artis-artis asal Korea Selatan sangatlah loyal dan royal terhadap idolanya. Mereka tak segan membawa benda seperti poster besar, spanduk dan light sign demi bisa mendapat perhatian dari sang artis, bahkan mereka rela menunggu sampai-berjam-jam demi bisa melihat artis tersebut hanya sekadar lewat di hadapan mereka.

\section{PEMBAHASAN}

A. Bahasa Korea merupakan hal yang utama.

Bahasa merupakan simbol yang disetujui dan digunakan bersama oleh sekelompok orang untuk menciptakan makna. Bahasa berperan dalam membentuk dan menyatakan identitas (Samovar, 2011). Melalui bahasa, kita dapat belajar nilai-nilai apa yang terkandung dan dianggap penting oleh sebuah budaya. Bahasa digunakan untuk menjamin keberadaan dan kelangsungan budaya.

Dalam video klip Nutrisari, video dibuka dengan sapaan dalam bahasa Korea: Annyeong haseyo, yang berarti ucapan salam selamat pagi, selamat siang, selamat sore, atau selamat malam. Setelah itu, Jung Min mengucapkan salam dalam bahasa Indonesia. Penggunaan bahasa Korea di awal sebelum penggunaan bahasa Indonesia dapat bermakna bahwa bahasa Korea lebih didahulukan daripada bahasa Korea. Ucapan salam yang dilakukan juga mengandung makna bahwa bahasa Korea seakan-akan menyapa dan memberi salam pada dunia.

Seperti diketahui, perkembangan bahasa Korea saat ini semakin meluas. Welle (2020) dalam tulisannya yang berjudul "Korea Selatan Ingin Dunia Belajar Bahasa Korea dengan KPop" menyatakan bahwa pemerintah Korea Selatan ingin memanfaatkan popularitas "gelombang Korea" untuk mempromosikan bahasa dan budaya bangsa merekad. Dengan meningkatkan penggunaan bahasa Korea, diharapkan dapat menjadi pintu gerbang bagi perkembangan bisnis, ekonomi, dan prestise nasional.

Lebih lanjut, Kementerian Kebudayaan, Olahraga, dan Pariwisata Korea Selatan mengumumkan bahwa mereka akan mengeluarkan dana sebesar $R p$ 1,1 triliun untuk mempromosikan alphabet Korea atau "Hangul". Angka ini merupakan tambahan sejumlah 300 miliar rupiah dibandingkan dana sebelumnya. Dana ini akan dipakai untuk meningkatkan 
pendidikan dan penyebaran bahasa Korea di luar negeri. Pemerintah Korea berharap dengan mempelajari bahasa ini akan membuat lebih banyak orang tertarik pada sejarah, seni, music, kuliner Korea, dan aspek lain dari budaya negara tersebut.

Valentina dan Istriyani (2013) menyatakan pula mengenai banyaknya universitas yang membuka jurusan atau studi tentang Korea Selatan. Hal ini dilakukan sebab banyak orang yang berminat untuk belajar dan mencari pengetahuan tentang Korea. Penggunaan bahasa Korea dalam iklan Jungmin pada awal video juga mengisyaratkan pentingnya menggunakan dan memahami bahasa Korea. Penggunaan salam tersebut juga mengisyaratkan bahwa "annyonghaseyo" telah mendunia dan semua masyarakat diyakini paham akan arti bahasa Korea tersebut.

\section{B. Seragam militer sebagai simbol kekuatan}

Dalam iklan Nutrisari, terlihat di awal video, Jung Min menggunakan jaket yang serupa dengan seragam militer dan dilengkapi dengan badge. Militer adalah angkatan bersenjata suatu negara yang dibentuk untuk menjaga dan melindungi negara dari serangan yang mengancam kedaulatan negara. Militer merupakan simbol kekuatan suatu negara.

Korea Selatan merupakan salah satu negara yang berdimensi maskulin, di mana memiliki ciri tegas, ambisius, kompetitif, serta berjuang untuk mencapai kesuksesan. Budaya maskulin seperti ini menghargai apa yang dianggap kuat, besar, dan cepat. (Samovar, 2011). Oleh karena itu, terdapat keharusan wajib militer bagi seluruh laki-laki yang menjadi warga negara Korea Selatan.

Alasan yang mendasari kenapa warga laki-laki di Korea Selatan harus menjalani wajib militer adalah terdapat ancaman berkelanjutan dari Korea Utara terhadap Korea Selatan mengenai serangan senjata nuklir. Wajib militer ini juga bertujuan untuk mempertimbangkan situasi keamanan di Korea Selatan pasca terpecahnya semenanjung Korea.

Dilansir dari KBS World, Lembaga analisis militer, Global Firepower (GFP) menempatkan Korea Selatan sebagai peringkat ke 6 dunia dalam kekuatan militer. Sementara itu, Korea Utara diketahui menempati urutan ke 25 di dunia. Urutan ini turun 7 peringkat dibandingkan setahun sebelumnya. Berdasarkan hal ini, diketahui kekuatan Korea Selatan jauh lebih unggul dibandingkan Korea Utara.

Jaket militer yang digunakan di dalam iklan memang tidak serupa persis dengan seragam militer asli Korea. Meskipun demikian, ini menjadi simbol yang cukup jelas untuk menyatakan bahwa Korea Selatan merupakan negara yang kuat dan berkuasa. Warna jaket yang merah juga melambangkan keberanian. Penggunaan jaket tersebut menjadi simbol kekuatan dan keberanian Korea Selatan.

\section{Korea Selatan sebagai kiblat fashion}

Dalam beberapa adegan, iklan Nutrisari Jung Min memperlihatkan gaya berpakaian yang cukup unik. Jung Min sempat mengenakan jaket orange terang dengan aksesoris yang menyala. Sementara itu, di adegan lainnya, terlihat penyanyi dan penari yang menggunakan pakaian mengkilap dengan potongan-potongan baju yang tidak biasa atau asimetris. Penggambaran seperti ini menunjukkan gaya fashion khas Korea Selatan.

Seiring dengan munculnya Korean wave, dunia fashion tidak lagi hanya berkiblat pada Paris, London, atau Jepang. Demam Korea pada beberapa tahun terakhir ini membawa Korea terutama Seoul menjadi salah satu yang diperhitungkan dalam dunia fashion. Gaya fashion yang yang dikenakan para selebriti maupun Kpop berhasil menghipnotis sekaligus memberikan pengaruh untuk para penggemarnya di seluruh dunia.

Berdasarkan penelitian Sari dan Sadewo (2015), diketahui bahwa Indonesia merupakan salah satu negara yang terpengaruh oleh budaya pop Korea. Terdapat fenomena di mana para remaja perempuan dan laki-laki terkena virus Korean wave di mana mereka mengikuti gaya yang ditampilkan idolanya seperti pakaian, make up, sampai pernak pernik yang dikenakan.

Fenomena berpenampilan inilah yang memicu timbulkan perubahan gaya sikap dan perilaku bagi para pecinta Korea khususnya di Indonesia. Bahkan saat ini budaya Korea juga 
dijadikan trendsetter dalam dunia fashion karena cara berpakaiannya yang memiliki ciri khas, unik, sehingga diminati para remaja. (Sari dan Sadewo, 2015).

D. Budaya tradisional sebagai identitas budaya

Penggambaran hanbok dan hanok pada iklan merupakan ciri khas dari budaya tradisional Korea yang masih dilestarikan hingga saat ini. Hanbok adalah pakaian sehari-hari orang Korea selama ribuan tahun lamanya. Meskipun pakaian Barat telah banyak menggantikan hanbok, tetapi umumnya orang Korea masih tetap memakainya untuk acaraacara khusus seperti pertemuan keluarga yang penting, liburan, pernikahan, dan pemakaman.

Hanbok umumnya memiliki warna yang cerah dengan garis yang sederhana, serta tidak memiliki saku. Pakaian ini mengacu kepada busana ala Dinasti Joseon yang biasa dipakai secara formal atau semiformal dalam perayaan atau festival tradisional. Hanbok memiliki beragam jenis dan terdapat sistem kasta di dalamnya. Bagi orang Korea, hanbok merupakan cerminan dari identitas budaya.

Serupa dengan hanbok, hanok merupakan rumah tradisional yang menjadi ciri khas budaya Korea. Bangunan hanok memiliki ciri khas dengan atap yang melengkung keluar dan pagar kayu yang menyerupai gerbang kecil. Desain rumah tradisional ini mencerminkan hubungan spiritual antara manusia dengan alam. Struktur bangunan juga mencerminkan kehidupan yang sederhana dan tenang.

Rumah-rumah hanok masih ada dan dilestarikan di Korea. Terdapat banyak desa di Korea yang mayoritas rumahnya bergaya hanok. Salah satunya adalah Bukchon Hanok Village yang digunakan sebagai pusat kebudayaan tradisional Korea, di mana para pengunjung dapat merasakan pengalaman seperti apa yang terjadi pada masa dinasti Joseon. Hanok juga merupakan identitas budaya Korea yang kuat.

\section{E. Korea Selatan sebagai pelopor Pop Culture}

Membicarakan Korean wave adalah membicarakan tentang Kpop. Kpop merupakan sebutan untuk musik pop Korea kepanjangan dari Korean pop. Dalam satu dekade terakhir, Kpop telah menjadi budaya populer yang mendunia. Budaya ini dengan sengaja dipasarkan ke dunia internasional sejalan dengan adanya dukungan dari pemerintahan Presiden Kim Dae Jung (Yeon, 2008). Di awal tahun 2000an, pemerintah mulai menargetkan ekspor budaya populer Korea sebagai bentuk inisiatif pelaksanaan sektor perekonomian baru. Pemerintah pun menyediakan alokasi dana sebesar 1,4 trilyun rupiah untuk penyebaran budaya popular Korea ini (Yeon, 2008).

Kpop menjadi budaya populer yang digunakan Korea Selatan bukan hanya dari musik, tetapi juga tarian yang menjadi "selling point" tersendiri. Di Korea, para anak dan remaja dididik dari kecil untuk menjadi cikal bakal pemusik, sementara para agensi musik pun mengadakan banyak audisi untuk penyanyi Kpop. Industri Kpop menjadi begitu penting. Black Pink dan BTS adalah contoh girlband dan boyband yang sangat sukses dan diminati banyak orang di seluruh dunia.

Kpop dalam iklan nutrisari Jung Min digambarkan dalam sebuah video klip penyanyi dan penari, pertemuan dengan para fans, dan juga kehadiran di sebuah acara award. Ketiga hal ini menggambarkan betapa Kpop identik dengan ketenaran dan kesuksesan yang mendunia.

\section{SIMPULAN}

Imperialisme budaya seyogyanya merupakan dominasi media budaya Barat di dunia. Seiring dengan berjalannya waktu, dominasi budaya tersebut tidak lagi berasal dari budaya barat. Penyebaran budaya popular Korea Selatan yang begitu masif menempatkan Korea sebagai pusat dari budaya dunia. Kpop, drama, fashion, makanan, dan berbagai sektor budaya lainnya telah disebarkan Korea Selatan ke segala penjuru dunia. Dalam kata lain, Korea telah melakukan imperialisme budaya. 
Selain musik video, salah satu penyebaran imperialisme budaya Korea adalah melalui iklan. Berdasarkan hasil analisis semiotika iklan Nutrisari versi Jung Min, diketahui iklan tersebut mengandung berbagai makna seperti pentingnya bahasa Korea, kekuatan militer Korea, Korea sebagai kiblat fashion, identitas budaya Korea yang kuat, serta budaya Kpop yang mendunia. Melalui analisis makna denotasi, konotasi, dan mitos, diketahui bahwa iklan Nutrisari versi Jung Min merupakan sebuah bentuk imperialisme di mana Korea adalah pusat dari segala budaya.

\section{DAFTAR PUSTAKA}

Al Kodri, M.A. (2016). Representasi Maskulinitas Boyband Shinee dalam Video Klip Ring Ding Dong melalui Ananlisis Semiotika. Bangka Belitung: Universitas Bangka Belitung.

Andreeany, J. (2018). Semakin Meledaknya Populasi Penyuka "Oppa" di Indonesia. Dari:https://www.kompasiana.com/jihanahn/5c0920796ddcae41ba19e7c7/semakinmeledaknya-populasi-penyuka-oppa-di-indonesia?page=all.

Ardia, V. (2014). Drama Korea dan Budaya Popular. Jurnal Lontar IImu Komunikasi Universitas Serang Raya, 2.3.

Danesi, M. (2010). Semiotika Media. Yogyakarta: Jalasutra.

Dewi, D.K.(2019). Musing Panas, Saatnya Mengintip Indahnya Hamparan Jutaan Bunga Matahari di Korea. Diakses dari: https://netz.id/gallery/2018/08/09/0071601716/1016080818/begini-indahnya-hamparan-jutaan-bunga-matahari-di-korea.

Febiola, M.M.(2017). Representasi Imperialisme Budaya Amerika dalam Music Video I Got a Boy. Jurnal E-Komunikasi Universitas Petra Surabaya. 5.2

Gogali, V.A. (2016). Industri Media dalam Budaya Popular Kajian Semiotika Pierce pada Drama Korea Saranghae. I Love You.Jurnal Komunikasi BSI Jakarta, 6.1.

Gora, R. (2016). Representasi Perempuan Dalam Iklan Televisi (Studi Analisis Semiotika Iklan Beng-Beng Versi "Great Value"). Jurnal Universitas Bunda Mulia, 165.

Kartinawati, E. (2014). Demam Korea dan Imperialisme Budaya (Kajian Booming Tayangan Korea terhadap Perubahan Perilaku di Masyarakat). Surakarta: Jurnal Universitas Sahid Surakarta.

Kodri, M.A. (2016). Representasi Maskulinitas Boyband Shinee Dalam Video Klip Ring Ding Dong Melalui Ananlisis Semiotika. Jurnal Society Universitas Bangka Belitung, 54

Malik, D.D. 2014. Globalisasi dan Imperialisme Budaya di Indonesia. Journal Communication Vol 5, No 2.

Nurudin. (2007). Pengantar Komunikasi Massa. Jakarta: Rajawali Press.

Nutrisari. (n.d). Deskripsi Nutrisari Rasa Jeju Orang. Diakses dari: https://www.nutrimart.co.id/nutrisari-jeju-orange-10

Putri, A.W. (2020). Penggemar K-Pop Indonesia adalah Ladang Emas Oppa Korea. dari: https://tirto.id/penggemar-k-pop-indonesia-adalah-ladang-emas-oppa-korea-eroc.

Radar Jogja (2019). Simple tapi Stylish! Intip Style ala Pria Korea, Dijamin Bikin Cewek Meleleh. Diakses dari: https://radarjogja.jawapos.com/2019/08/20/simple-tapi-stylish-intip-styleala-pria-korea-dijamin-bikin-cewek-meleleh/.

Rachel, J. (2017). 5 Alasan Korea Selatan Pantas Menjadi Negara Inspirasi Fashion. Diakses dari: $\quad$ http://www.cosmogirl.co.id/artikel/read/9490/5-Alasan-Korea-Selatan-PantasMenjadi-Negara-Inspirasi-Fashion.

Samovar, L.A., Porter, R.E. \& McDaniel, E.R. (2009). Communication Between Cultures. USA: Wadsworth.

Sari, N.S. \& Sadewo, F.X.S.(2015). Korean Fashion Style (Praktik Sosial Pola Berpakaian Pengguna Korean Style di Surabaya). Jurnal Paradigma. Hal 1-7. Vol 3 no 3.

Shim, D. (2006). Hybridity and the rise of Korean popular culture in Asia. Media, Culture \& Society. Singapura: National University of Singapore. 
Vitaarum, W. (2016), Jeju Island Korea Selatan - Serba-Serbi Olahan Jeruk Buah Tangan Khas Pulau Samdado. Diakses dari: https://travel.tribunnews.com/2016/08/04/jeju-islandkorea-selatan-serba-serbi-olahan-jeruk-buah-tangan-khas-pulau-samdado.

Wahyuningratna, R.N, Saputra, W.T., (2018). Ragam Representasi Iklan Sensual di Televisi (Kajian Semiotika Roland Barthes). Bandung: Jurnal Dialektika Universitas LangLang Buana.

Welle, D. (2020). Korea Selatan Ingin Dunia Belajar Bahasa Korea dengan K-Pop. Diakses dari: news.detik.co/dw/d-5208320-korea-selatan-ingin-dunia-belajar-bahasa-korea-dengankpop

Yeon, S.S. (2008). Why Are Asians Attracted to Korean Pop Culture: Korean Wave. Ed. The Korea Herald. Seoul: Jimoondang.

Zetizen.(2016). 5 Fakta Menarik Drama Korea "Moon Lovers: Scarlet Heart Ryeo". Diakses dari: https://zetizen.jawapos.com/show/3042/5-fakta-menarik-drama-korea-moon-loversscarlet-heart-ryeo 